\section{Determination of a Biologically Active Peptide Split off from Plasma Protein}

\section{$\mathrm{U} 11$ a $\mathrm{H}$ a m berg}

Department of Pharmacology, University of Helsinki, and Biochemical Institute, Helsinki, Finland

Biologically active peptides with smooth muscle contracting properties can be split off from the $\alpha_{2}$-globulins in blood plasma by proteolytic enzymes, such as trypsin and plasmin, or by an hitherto unidentified activation of endogenous plasma enzyme(s). The recent isolation and chemical identification of two such peptides from human plasma, brady. kinin ${ }^{1,2}$ and kallidin ${ }^{3}, 4$, opens aspects regarding the possible physiological role of these smooth muscle contracting and hypotensive polypeptides presumably released from the same protein fraction in blood plasma. In vitro studies concerning the mode of bradykinin release with plasma of various species, rat, bovine and human, sustained that the peptide may be released by activation processes resembling the fibrinolytic activation in plasma, known to occur in many physiological and pathological conditions.

The small quantities in which these peptides are obtained from plasma is a limiting factor for their study. Most of the work so far concerning these so called plasma kinins ${ }^{5}$ relies upon unspecific pharmacological bioassay methods, which however have the advantage of requiring very small amounts of material due to the high biological activity of these peptides. The chemical similarity between bradykinin and kallidin, which are peptide homologues, rises the question as to which one of the peptides may be released under various conditions.

Bradykinin was released in vitro by a spontaneous activation process in human plasma. It was isolated and identified using the DNP. method for the estimation of the molar distribution of amino acids. Purification was performed by using extraction, ionexchange chromatography, paper electrophoresis and chromatography with an over-all recovery of approximately $25-30 \%$ of the active peptide. The molar proportions of the DNP-amino acids obtained with hydrolyzed material indi- cated that bradykinin was obtained essentially pure. An approach was therefore made to estimate small amounts of isolated peptide by determination of its arginine content. The bioassay performed on the guinea pig ileum gave an activity ratio of close to unity, when the human peptide was compared with synthetic bradykinin ${ }^{6}$ in equimolar concentrations estimated by the arginine content. Chemical analyses of pure isolated bradykinin were performed with $25-100 \mu \mathrm{g}$ of peptide, which was found sufficient to obtain the molar proportions of arginine (2), glycine (1), serine (1), phenylalanine (2) and proline (3) in bradykinin as the respective DNP-derivatives.

A difference in the degree of smooth muscle contracting properties ${ }^{7}$ and the endgroup lysine ${ }^{4}$ distinguishes kallidin from bradykinin, which otherwise contain the same nine amino acids mentioned above. Contamination with kallidin was ruled out under the present experimental conditions used for the release of the human peptide, since the biological activity per mole of peptide, estimated as arginine, corresponded to that of the synthetic bradykinin. Identification of plasma kinins is therefore possible as far as these two peptides are concerned, even with rather limited amounts of material, which otherwise may be insufficient for the complete structure determination by chemical or enzymatic degradation.

This research has been supported by a grant from the Signe and Ane Gyllenberg Foundation

1. Rocha e Silva, M., Beraldo, W. T. and Rosenfeld, G. Am. J. Physiol. 156 (1949) 261.

2. Hamberg, U. Isolation of bradykinin from human plasma. Mode of release, amino acid composition and molar activity, (Diss.) Ann. Acad. Sci. Fennicae A II, 1962 No. 113.

3. Werle, E., Trautschold, I. and Leysath, G. Z. physiol. Chem. 326 (1961) 174.

4. Pierce, J. V. and Webster, M. E. Biochem. biophys. Res. Commun. 5 (1961) 353.

5. Lewis, G. P. J. Physiol. 140 (1958) 285.

6. Boissonnas, R. A., Guttmann, St. and Jaquenoud, P.-A. Helv. Chim. Acta 43 (1960) 1349.

7. Pless, J., Stürmer, E., Guttmann, St. and Boissonnas, R. A. Helv. Chim. Acta 45 (1962) 394. 